Fig. 1. Mean skin coverage in $\%$ and range of distribution with different volume/time combinations using fluorescent marker in alcoholic hand disinfectant.

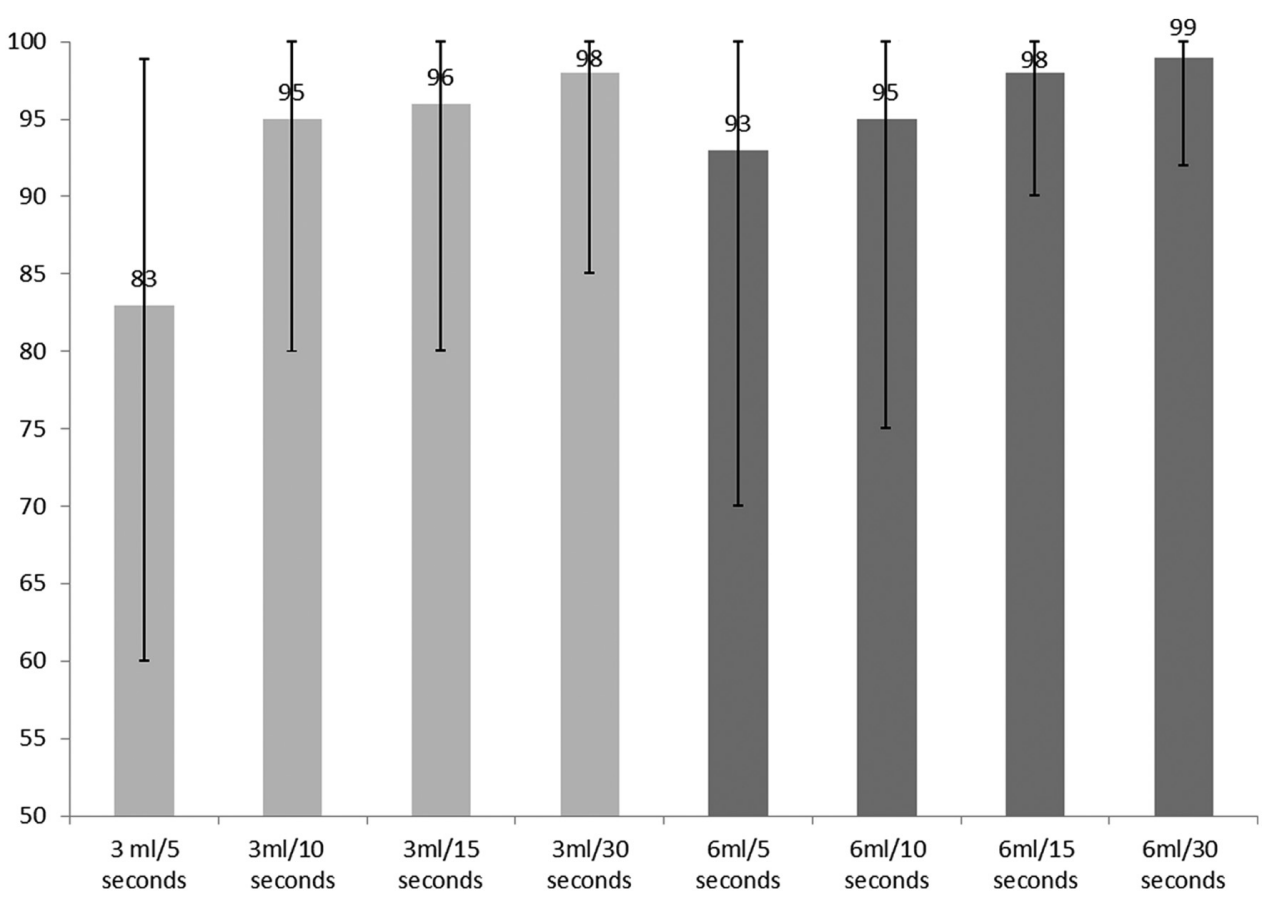

\section{Acknowledgments. None.}

Financial support. This work was funded by institutional funds only.

Conflicts of interest. S.S.S. is a shareholder of BZH-Beteiligungs-GbR and receives royalties from Springer, Thieme, and Consilium infectiorum. T.H. is a shareholder of BZH-Beteiligungs-GbR and receives royalties from Springer, Elsevier, and Thieme.

\section{References}

1. Kramer A, Pittet D, Klasinc R, Krebs S, Koburger T, Fusch C, Assadian O. Shortening the application time of alcohol-based hand rubs to 15 seconds may improve the frequency of hand antisepsis actions in a neonatal intensive care unit. Infect Control Hosp Epidemiol 2017;38:1430-1434.

2. Schulz-Stübner S, Volkmann A, Ebner W, Hauer T. Practice and attitudes toward alcohol based hand disinfection among German infection control teams. Infect Control Hosp Epidemiol 2019;40:609-612.

3. Deutsche Gesellschaft für Krankenhaushygiene (DGKH)/German Society of Hospital hygiene. Stellungnahme des Vorstandes der DGKH zur
Verkürzung der Einwirkzeit der Händedesinfektion von 30 aus 15 Sekunden [Statement of the DGKH board in regard to shortening the recommendation for hand disinfection from 30 to 15 seconds. Hyg Med 2019;44:190-191.

4. Stahmeyer JT, Lutze B, von Lengerke T, Chaberny IF, Krauth C, Hand Hygiene in intensive care units: a matter of time? J Hosp Infect 2017;95: 338-343.

5. Pires D, Spule H, Bellissimo-Rodrigues F, Gayet-Ageron A, Pittet D. Hand hygiene with alcohol-based hand rub: how long is long enough? Infect Control Hosp Epidemiol 2017;38:547-552.

6. Tschudin-Suter S, Rotter ML, Frei R, et al. Simplifying the WHO 'how to hand rub' technique: three steps are as effective as six-results from an experimental randomized crossover trial. Clin Microbiol Infect 2017;23: 409.e1-409.e4.

7. Tschudin-Sutter S, Sepulcri D, Dangel M, Ulrich A, Frei R, Widmer AF. Simplifying the WHO protocol: three steps versus six steps for performance of hand hygiene-a cluster-randomized trial. Clin Infect Dis 2018 Nov 3. doi: $10.1093 /$ cid/ciy 948 .

\title{
The varying specificity of urine cultures in different populations
}

\section{Kirk M. Chan-Tack MD ${ }^{1,2}$ (D), Barbara W. Trautner MD, $\mathrm{PhD}^{3,4}$ and Daniel J. Morgan MD, MS ${ }^{1,5}$}

${ }^{1}$ Veterans' Affairs Maryland Health Care System, Baltimore, Maryland, ${ }^{2}$ Center for Drug Evaluation and Research, Food and Drug Administration, Silver Spring, Maryland, ${ }^{3}$ Center for Innovations in Quality, Effectiveness, and Safety at the Michael E. DeBakey Veterans' Affairs Medical Center, Houston, Texas, ${ }^{4}$ Department of Medicine, Baylor College of Medicine, Houston, Texas and ${ }^{5}$ Division of Genomic Epidemiology and Clinical Outcomes, Department of Epidemiology and Public Health, Baltimore, Maryland

\footnotetext{
Author for correspondence: Daniel J. Morgan MD, MS, Epidemiology and Public Health,

University of Maryland School of Medicine, 10 S Pine St, Medical School Teaching Facility 334, Baltimore, MD 21211. E-mail: dmorgan@som. umaryland.edu

Cite this article: Chan-Tack KM, Trautner BW, and Morgan DJ. (2020). The varying specificity of urine cultures in different populations. Infection Control \& Hospital Epidemiology, 41: 489-491, https://doi.org/10.1017/ice.2020.16
}

To the Editor-Diagnostic testing is essential in distinguishing patients who have a disease from those who do not. The accuracy of a test is described by sensitivity and specificity. Sensitivity reflects how many patients with disease have a positive test, and specificity reflects how many patients without disease have a 
negative test. When a test is applied to different populations, pretest probability changes, but not sensitivity or specificity because these are inherent characteristics of the test. ${ }^{1}$ However, clinical experience suggest that urine cultures and other tests do not have fixed testing characteristics and that specificity can and does vary by population. We sought to explore the rule that sensitivity and specificity are fixed using a commonly ordered test-the urine culture.

Laboratory values reflect underlying microbiology, physiology, or biochemistry and must be accurate and consistent, but to be clinically useful a diagnostic test must distinguish patients with and without clinical disease. Urinary tract infection (UTI) requires symptoms in addition to the presence of a microorganism. For microbiology tests, positive results indicating the presence of a potentially pathogenic organism in the absence of symptomatic disease are common and are known as asymptomatic colonization or asymptomatic bacteriuria (ASB). Treatment of ASB is a leading cause of antibiotic overuse. ${ }^{2}$ Urine cultures are among the most commonly ordered tests but are often misinterpreted, especially in older, sicker populations.

We searched the English-language medical literature using the terms urine culture, urinary tract infection, and sensitivity or specificity. This search was supplemented by a manual review of the bibliographies of all identified articles. One author (K.C.T) initially screened the titles and abstracts of the search results. Two authors (K.C.T and D.J.M.) then independently reviewed and abstracted data from the articles identified as relevant.

We identified 1,075 articles, of which 18 satisfied the criteria of reporting sensitivity or specificity of urine cultures. ${ }^{2-7}$ Of these, 13 were summarized in 1 guideline. ${ }^{2}$ Articles were analyzed for sensitivity and specificity using $10^{5}$ colony-forming units per milliliter as the criteria for comparison (Table 1). For multiple studies of the same population, a weighted average for sensitivity and specificity was calculated.

Urine cultures had a sensitivity of $\sim 90 \%$ for UTI in healthy outpatient women (Table 1). We found no studies of the sensitivity of urine cultures for other populations. We found highly variable specificity for urine culture to identify UTI, from $80 \%-90 \%$ in healthy outpatients down to nearly $0 \%$ in patients with chronic indwelling catheters.

The specificity of urine cultures varies greatly by population, from $0 \%$ to $90 \%$, which contradicts the rule that the specificity of a diagnostic test does not change by population. This finding has broad implications for urine testing and treatment in different patient groups. Biologically, this variability in specificity results from different populations having factors that lead to chronic bacterial colonization, leading to false-positive results in patients without symptoms of UTI. Although urine cultures are accurate for presence of bacteria, they are nonspecific for the presence of clinical UTI. Other examples of widely used tests in which sensitivity or specificity vary by population are Clostridium difficile $^{8}$ and B-type natriuretic peptide (BNP). ${ }^{9}$

Correct application of diagnostic testing is complex. Appreciating potential variation in specificity by population tested is important for patient care. With urine cultures, treatment of false-positive urine cultures, or ASB, risks antibiotic exposure without clinical benefit. Varying specificity for this test across populations emphasizes the need to identify sensitivity and specificity within similar populations to the ones that the test will be applied to, and potentially determine, sensitivity and specificity for multiple populations. In an age of electronic records, the reporting of urine cultures and the predictive value of the results
Table 1. Sensitivity, Specificity and Clinical Usefulness of Urine Culture for Diagnosis of Urinary Tract Infection (UTI) in Different Patient Populations

\begin{tabular}{|c|c|c|c|}
\hline Patient Population & Sensitivity, \% & Specificity, \% & Clinical Use \\
\hline $\begin{array}{l}\text { Healthy outpatient } \\
\text { women }^{2-7}\end{array}$ & 90 & 86 & $\begin{array}{l}\text { Can confirm } \\
\text { diagnosis of UTI } \\
\text { in patient with } \\
\text { symptoms }\end{array}$ \\
\hline $\begin{array}{l}\text { Elderly outpatients } \\
\text { (age } \geq 70 \text { ys) }^{2}\end{array}$ & a & 90 & $\begin{array}{l}\text { Can confirm } \\
\text { diagnosis of UTI } \\
\text { in patient with } \\
\text { symptoms }\end{array}$ \\
\hline $\begin{array}{l}\text { Elderly in long- } \\
\text { term care facility } \\
(\text { age } \geq 70 \mathrm{y})^{2}\end{array}$ & a & 70 & $\begin{array}{l}\text { Small impact on } \\
\text { diagnosis, helps } \\
\text { for antibiotic } \\
\text { selection }\end{array}$ \\
\hline $\begin{array}{l}\text { Chronically ill } \\
\text { (diabetes; kidney } \\
\text { transplant) }\end{array}$ & a & $76-95$ & $\begin{array}{l}\text { Small impact on } \\
\text { diagnosis, helps } \\
\text { for antibiotic } \\
\text { selection }\end{array}$ \\
\hline 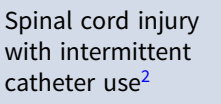 & a & 54 & $\begin{array}{l}\text { Only useful for } \\
\text { antibiotic } \\
\text { selection }\end{array}$ \\
\hline $\begin{array}{l}\text { Spinal cord } \\
\text { injury with } \\
\text { sphincterotomy/ } \\
\text { condom catheter }^{2}\end{array}$ & a & 43 & $\begin{array}{l}\text { Only useful for } \\
\text { antibiotic } \\
\text { selection }\end{array}$ \\
\hline $\begin{array}{l}\text { Acute indwelling } \\
\text { catheter use }{ }^{2}\end{array}$ & a & $\begin{array}{l}\text { Decreases } \\
\text { 3\%-5\% per } \\
\text { catheter day }\end{array}$ & $\begin{array}{l}\text { Varies by } \\
\text { duration of } \\
\text { catheter use }\end{array}$ \\
\hline $\begin{array}{l}\text { Chronic indwelling } \\
\text { catheter use }{ }^{2}\end{array}$ & a & 2 & $\begin{array}{l}\text { Only useful for } \\
\text { antibiotic } \\
\text { selection }\end{array}$ \\
\hline
\end{tabular}

Note. For brevity, studies of specificity are summarized in the Infectious Disease Society of America guidelines for management of asymptomatic bacteriuria (ASB). ${ }^{2}$ These guidelines report false-positive rate or ASB, which is 1-specificity. When rates of ASB are described, this is the false positive rate of urine culture testing, which was calculated as 1-specificity of the test. ${ }^{a}$ No studies identified reported sensitivity of urine cultures in these populations. ${ }^{\mathrm{b}} \mathrm{The}$ prevalence of asymptomatic bacteriuria or a positive urine culture without UTI increases $3 \%-5 \%$ per day of catheterization, therefore the specificity decreases by $3 \%-5 \%$ per day.

could easily be tailored to the type of patient tested. Additionally, the varied specificity of urine cultures means we need different diagnostic stewardship for urine cultures in long-term care, inpatient care, and outpatient care settings. ${ }^{10}$ By appreciating the nuances of diagnostic testing for UTI and other diseases, we can leverage currently available technology to provide better diagnoses and patient care.

Acknowledgments. The participation of coauthor K.C.T should not be construed to represent the views or policies of the US Food and Drug Administration. The views expressed in this article are those of the authors and do not necessarily reflect the position or policy of the Department of Veterans' Affairs or the US government.

Financial support. D.J.M. reports funding from the National Institutes of Health, the Centers for Disease Control and Prevention, the Agency for Healthcare Research and Quality (AHRQ) and US Department of Veterans' Affairs (VA). B.W.T. reports funding from the VA Office of Rehabilitation Research and Development, the VA Health Services Research and Development Service, and the AHRQ. Her work is supported in part by the Department of Veterans' Affairs, Veterans' Health Administration, Office of Research and Development, and the Center for Innovations in Quality, Effectiveness, and Safety (grant no. CIN 13-413). K.C.T. - None.

Conflicts of interest. All authors have no potential conflicts of interest related to this article. 


\section{References}

1. Iorio A, Spencer FA, Falavigna M, et al. Use of GRADE for assessment of evidence about prognosis: rating confidence in estimates of event rates in broad categories of patients. BMJ 2015;350:h870.

2. Nicolle LE, Gupta K, Bradley SF, et al. Clinical practice guideline for the management of asymptomatic bacteriuria: 2019 update by the Infectious Diseases Society of America, Clin Infect Dis 2019;68:e83-110. doi: 10.1093/cid/ciy1121.

3. Córdoba G, Holm A, Sørensen TM, et al. Use of diagnostic tests and the appropriateness of the treatment decision in patients with suspected urinary tract infection in primary care in Denmark-observational study. BMC Fam Pract 2018;19:65.

4. Pernille H, Lars B, Marjukka M, Volkert S, Anne H. Sampling of urine for diagnosing urinary tract infection in general practice-first-void or mid-stream urine? Scand J Prim Health Care 2019;37:113-119.
5. Hooton TM, Roberts PL, Cox ME, Stapleton AE. Voided midstream urine culture and acute cystitis in premenopausal women. $N$ Engl J Med 2013;369:1883-1891.

6. Walter FG, Knopp RK. Urine sampling in ambulatory women: midstream clean-catch versus catheterization. Ann Emerg Med 1989;18:166-172.

7. Stamm WE, Counts GW, Running KR, Fihn S, Turck M, Holmes KK. Diagnosis of coliform infection in acutely dysuric women. $N$ Engl J Med 1982;307:463-468.

8. Bagdasarian N, Rao K, Malani PN. Diagnosis and treatment of Clostridium difficile in adults: a systematic review. JAMA 2015;313:398-408.

9. Taylor KS, Verbakel JY, Feakins BG, et al. Diagnostic accuracy of pointof-care natriuretic peptide testing for chronic heart failure in ambulatory care: systematic review and meta-analysis. BMJ 2018;361:k1450.

10. Morgan DJ, Malani P, Diekema DJ. Diagnostic stewardship-leveraging the laboratory to improve antimicrobial use. JAMA 2017;318:607-608.

\section{The Hawthorne effect in observational studies:Threat or opportunity?}

\section{Mostafa Mostafazadeh-Bora MSc}

North Khorasan University of Medical Sciences, Bojnurd, Iran

To the Editor-In the December 2019 issue of Infection Control and Hospital Epidemiology, Mills et $\mathrm{al}^{1}$ described factors that influence hand hygiene compliance in nursing facilities. Direct observation is used for data collection in this study. One of the problems in observational studies is the Hawthorne effect. However, insufficient control for the Hawthorne effect is a major problem in observational studies.

Hand hygiene $(\mathrm{HH})$ is a simple way to prevent healthcare-associated infections (HAIs). Several methods can be used to measure $\mathrm{HH}$, such as direct observation and measuring the amount of solutions used for hand hygiene (soap and alcoholic ingredients), but direct observation is a key standard method recommended by the World Health Organization. ${ }^{2}$ In this method, the observer reviews the behavior of individuals in terms of performance. The first problem occurs because people often change their behavior when they know they are being observed. In fact, change in behavior and performance in the presence of an observer, termed reactivity, can influence the $\mathrm{HH}$ compliance rate and may not be an accurate representation of that behavior. Therefore, it is necessary to control reactivity in observational studies. ${ }^{3}$

The control of reactivity in research can be achieved using several methods. First, behavior can be measured when people do not know they are being assessed. In other words, observation is unobtrusive (nonreactive). ${ }^{3}$ This approach can be applied in various ways, including hiding the observer or using hidden mechanical recording devices. Adaptation of participants to the presence of an observer through habituation or desensitization is another way to inhibit reactivity. In the habituation approach, the observer explains the process of the project to the participant engaged in clinical activities, and the observer is present on different occasions until the participant no longer reacts to being observed. Limiting the reactivity response through desensitization is similar to the desensitization process used in the behavioral treatment of phobias. This approach is often used by ethologists to adapt animal subjects to the presence of an observer. ${ }^{3}$

Reactivity is major problem that can increase error in measurements in observational studies. Attention to this problem from researchers who perform observational studies is an important first step. To control for reactivity in observational studies, it may be necessary to introduce oneself in different clinical settings.

Acknowledgments. None.

Financial support. No financial support was provided relevant to this article.

Conflict of interest. The author declares no conflict of interest.

\section{References}

1. Mills JP, Zhu Z, Mantey J, et al. The devil is in the details: factors influencing hand hygiene adherence and contamination with antibiotic-resistant organisms among healthcare providers in nursing facilities. Infect Control Hosp Epidemiol 2019;40:1394-1399.

2. Measuring hand hygeine adherence: overcoming the challenges. The Joint Commission website. https://www.jointcommission.org/-/media/deprecatedunorganized/imported-assets/tjc/system-folders/topics-library/hh_mono graphpdf.pdf?db=web\&hash=7F1A70731D44DC2D183B1038CE34EC46. Published 2009. Accessed January 20, 2020.

3. Wilson S, MacLean R. Research Methods and Data Analysis for Psychology. New York: McGraw-Hill Higher Education; 2011.
Author for correspondence: Mr. Mostafa Mostafazadeh-Bora, E-mail: mostafamostafaz adehbora2014@yahoo.com

Cite this article: Mostafazadeh-Bora M. (2020). The Hawthorne effect in observational studies:Threat or opportunity?. Infection Control \& Hospital Epidemiology, 41: 491, https:// doi.org/10.1017/ice.2020.19 